\title{
WHAT DO UNIVERSITY PATENT ROUTES INDICATE AT REGIONAL LEVEL?
}

\author{
Joaquín M. Azagra-Caro*, Alfredo Yegros-Yegros, Fragiskos Archontakis \\ Institute of Innovation and Knowledge Management (INGENIO), CSIC-UPV \\ Universidad Politécnica de Valencia, Camino de Vera s/n, 46071 Valencia, Spain
}

This version: 10/02/2009

\begin{abstract}
We estimate the determinants of university patents by route in Spain. National patents are an indicator of R\&D efforts when we focus on the region, but not of how regions organize their university or joint research structure. International patents are a stronger indicator of R\&D efforts, so they express confidence in the potential of the patent. Neither set is an indicator of proximity to the region's competencies in technologies other than for production-intensive sectors, so they will not always foster regional technology transfer. Since the driving forces of national and international patents differ, the use of both is recommended.
\end{abstract}

Keywords: university patents, scientific productivity, technology transfer

\section{Introduction}

In newspapers, political programmes, university reports and industrial liaison offices’ leaflets, we usually observe a positive state of opinion regarding university patents ${ }^{1}$. Some theoretical approaches support these views. For Clark (1998: p. 7), “entrepreneurial universities learn faster than non-entrepreneurial counterparts that money from many sources enhances the opportunity to make significant moves”. For supporters of the Triple Helix approach, the differences between basic and applied research are eventually blurring so most productive faculty generate publications as well as patents (Etzkowitz, 1998).

Other voices have been more critical. The economics of science approach (Dasgupta and David, 1994) pointed to the substitutive effects between R\&D leading to patents, and other

\footnotetext{
* Corresponding author. Tel: +34 963877 048; fax: +34 963877 091; e-mail address: jazagra@ingenio.upv.es.

${ }^{1}$ We will use this term for patents applied for by universities. On patents with university inventors applied for by other institutions, see Meyer-Krahmer and Schmoch (1998), Azagra et al. (2005) and Meyer (2004).
} 
research which provides less tangible but wider benefits. Other studies have enumerated these indirect benefits in some detail (Scott et al., 2002).

These conflicting views make university patents a relevant topic for policymaking. Underlying them is the issue of what they are indicators for: R\&D productivity? Technology transfer? Our main interest is to focus the debates in a regional context: Do we confirm empirical findings on university patents of studies at sub-regional level when we analyse the regional level, e.g. regarding their relation to $R \& D$ expenditure? Can regions as a unit of observation offer stimulating findings that studies at sub-regional level do not cover? Do university patents applied for through a domestic patent office behave differently from those applied for through a foreign office, and consequently make the answers to the above questions vary?

The rest of this paper follows the traditional structure to find some answers. Section 2 presents the literature review. Section 3 describes the methodology and the data used to expand our knowledge. Section 4 gives the results. Section 5 reaches some conclusions.

\section{Literature review}

\subsection{University patents at sub-regional level}

Several studies apply econometric techniques to estimate the relation between university patents and different explanatory variables. Five use universities as a unit of observation, in the US case (Foltz et al., 2000; 2001; Carlsson and Fridh, 2002; Payne and Siow, 2003; Coupé, 2003). Two of them refer to the department or laboratory level of single European universities (Azagra et al., 2003, 2005). One uses individuals as the unit of observation, from two MIT departments (Agrawal and Henderson, 2002). In all these studies university patenting application takes place through national patent offices. 
The most frequent determinant included is R\&D expenditure. Carlsson and Fridh (2002) find a significant positive impact of aggregate $R \& D$ on the number of disclosures. Payne and Siow (2003) and Coupé (2003) conclude that the returns of federally funded R\&D to patents are decreasing. Foltz et al. (2000) find the sum of federal and state funding positive and significant for all university patents but not significant for agricultural biotechnology university patents. Foltz et al. (2001) find that state funding has a positive, significant, influence on agricultural biotechnology university patents while federal funding has not. Azagra et al. (2003) find more costly, long-term-oriented, public funds significant, but not less costly, short-term-oriented ones. Azagra et al. (2005) find regional public funds significant. Hence, it seems reasonable to propose the following hypothesis:

Hypothesis 1. The higher the amount of R\&D funds, the more likely it is that universities will generate national patents.

A second usual determinant of university patents is size. Foltz et al. (2001) and Payne and Siow (2003) do not find the number of faculty significant but Coupé (2003) does. Azagra et al. (2003) do not find it significant but Azagra et al. (2005) do. Overall, the evidence is not conclusive. We will state the following hypothesis with the expectation of a positive sign:

Hypothesis 2. The higher the number of researchers, the more likely it is that universities will generate national patents.

Other determinants are external forces that grow as time goes by. ${ }^{2}$ Coupé (2003) finds a trend variable positive and significant. Azagra et al. (2003) find it significant but Azagra et al. (2005) do not. The explanation may be in the national features of the forces lying behind the

\footnotetext{
${ }^{2}$ This is not to say that there are no more determinants of university patenting, e.g. faculty quality (Foltz et al., 2001, Coupé, 2003) or patenting and publishing experience (Foltz et al., 2001, Agrawal and Henderson, 2002).
} 
trend: strength of technology transfer offices (TTO), university R\&D spillovers, legal framework, etc. Consequently, this is the hypothesis we want to test:

Hypothesis 3. Over time, external forces make the number of national university patents increase.

\subsection{Universities and the region}

One may distinguish among types of universities according to the historical period of their creation, e.g. medieval, contemporary and post-World War II universities (Geuna, 1999). One may think of different technical orientations (polytechnics and other) or regimes of ownership (public or private), etc. These differences may be relevant for the production of university patents. Coupé (2003) makes a distinction between public and private universities but he does not find significant differences. Mowery and Sampat (2001) show that, according to the prevailing incentives at a particular time, public or private universities will change their interest in patenting. In any case, regions may contain different numbers and types of universities. This motivates the following hypothesis:

Hypothesis 4. University structure matters: the number of universities and their composition according to their age, technical orientation or regime of ownership will influence the generation of national patents.

The existence of joint research centres between universities and public research organisations (e.g. CNRS in France, CNR in Italy, CSIC in Spain) implies access to cultural and functional features that lead to higher application for patents, e.g. their preference for research leading to practical applications as compared to universities (Cesaroni and Piccaluga, 2002) or the lack of teaching responsibilities. Azagra et al. (2003) show that the presence of a 
joint research centre at a university increases its propensity to patent. For these reasons, we present the following hypothesis:

Hypothesis 5. Joint research structure matters: the higher the number of joint research centres between universities and other public research organisations, the more likely it will be that universities generate national patents.

A traditional argument to support university patents is their positive effects on technology transfer. Our point is that, if patents enhance technology transfer, is this to institutions located within the region? Assuming that universities would like to contribute to regional development through increased technology transfer, a necessary step would be for universities to adapt their fields of expertise to other institutions in the region. If universities think that patenting will facilitate this process of adaptation, i.e. patenting in the same technological fields as other local institutions, reducing the distance between universities and other institutions will be an incentive for further patenting. This argument leads us to present the following hypothesis:

Hypothesis 6. The shorter the technological distance to other institutions, the more likely it will be that universities generate national patents.

\subsection{Routes of patenting}

Sovereign states legislate on intellectual property rights. Inventors can apply for a patent through their respective national patent offices. Most developed countries have eventually allowed universities to apply for patents and license them. It varies who retains the ownership and who retains the inventorship, e.g. the university or the inventor. If there is a license, it also varies how they will share the royalties. Very often, governments delegate the issue to the internal regulation of the universities. 
Patent application is subject to payment of fees. In some countries, like Spain, universities are exempt from this charge and hence, it is relatively cheap for them to apply for a patent through the national patent office.

There are some other routes to protect inventions in the home country. States may agree to sign international treaties such as the Patent Cooperation Treaty, which gave rise to the socalled PCT patent, and the European Patent Agreement, which gave rise to the so-called European Patent). In both cases, universities are not exempt from fee payment, and fees tend to be higher than national ones.

For each European or PCT patent, it is common to find a previous national application. This is enough to formulate the next hypothesis:

Hypothesis 7. The higher the number of past national university patents, the more likely it will be that universities generate international patents.

In addition, we may wonder whether to follow one route of patenting or the other is subject to the same process. Therefore, we set the following hypothesis:

Hypothesis 8. Other than past national patents, the determinants of national and international university patents are coincident.

\section{Methodology and data}

The sample contains data about Spain, for a 14 year-period and 17 autonomous regions. The resulting database is therefore a 238-observation panel.

The dependent variables comprise Spanish university patents in the period 1988-2001. Data come from the Spanish Patent and Trademark Office (OEPM). Our period of observation begins from 1988 because data for some independent variables start in 1987 and we assume, 
at least, a one-year lag with them in order to prevent endogeneity as much as possible. The last year is 2001 because of the delay of updating.

We identified all patents with at least one Spanish university among the applicants. As we may see in Table 1 , we found 1,479 patents. We assigned patents to regions according to the main site of the university. When more than one university appeared in the list of applicants, we chose to assign one patent per university. This way, we counted 1,519 patents. Most of them are national patents because international patents imply higher costs and requirements. In addition, while most national patents are grants, most international patents are applications, due to the delay of the granting process.

Taking all this into consideration, we defined the next variables for the estimations:

Natpat: number of Spanish university patents applied for through the national route.

Natgrant: number of Spanish university patents granted through the national route.

Intpat: number of Spanish university patents applied for through an international route, i.e. the sum of both European and PCT patents.

Table 1. Distribution of real and counted patents by route of patenting

\begin{tabular}{lcccc}
\hline & Real patents & & \multicolumn{2}{c}{ Counted patents } \\
\cline { 2 - 5 } & Total & Applied patents & Granted Patents & Total \\
\hline National patents & 1398 & 264 & 1172 & 1436 \\
\hline International patents & 81 & 63 & 20 & 83 \\
\hline TOTAL & 1479 & 327 & 1192 & 1519 \\
\hline
\end{tabular}

Source: OEPM: Cibepat and own elaboration.

In order to find the adequate estimation technique, we must take into account that patents are count data. The baseline model is the Poisson regression model (PRM), which holds under the assumption of equidispersion. An extension is the Negative Binomial Regression Model (NBRM), which relaxes this assumption. However, one might argue that different reasons cause the presence of zeros. Zero-inflated count models respond to this failure. 
Because of the small number of international patents, we followed an alternative approach by creating the following variable:

Intpat2: having at least one university patent, applied for through an international route.

A more appropriate technique of estimation for intpat2 is the Probit Model.

A first set of data on independent variables comes from the National Statistics Institute:

Lherd: logarithm of the real value of university R\&D expenditure.

Lfte: logarithm of the number of Full Time Equivalent (FTE) researchers.

We also introduce the following variable:

Trend: year of the patent application.

Aspects concerning university structure come from the Universia.es portal ${ }^{3}$ :

Lnum: logarithm of the number of universities.

Univst1: classification of universities according to their regime of ownership and being a polytechnic. Ppub is the proportion of public, non-polytechnic universities, ppol of polytechnic universities and ppriv of private universities.

Univst2: classification of universities according to epoch of creation (Geuna, 1999; Rodríguez-San Pedro, 2004): pmed is the proportion of medieval universities, pmod of modern universities, pcont of contemporary universities and prec of recent universities.

From CSIC reports, we build the variables regarding other public research infrastructure:

Ljoi: logarithm of the number of university-CSIC joint research centres.

Pjoi: ratio of number of university-CSIC joint research centres to number of universities.

Table 2 shows descriptive statistics.

\footnotetext{
${ }^{3}$ http://www.universia.es.
} 
Table 2. Descriptive Statistics of independent variables ${ }^{4}$. N=238.

\begin{tabular}{lllll}
\hline Variable & Mean & Std.Dev. & Minimum & Maximum \\
\hline Herd & 34341.6 & 39254 & 0 & 157684 \\
\hline Fte & 1385.13 & 1615.24 & 0 & 7802 \\
\hline Num & 3.13866 & 3.11009 & 0 & 14 \\
\hline Ppub & 0.845971 & 0.214805 & 0.333333 & 1 \\
\hline Ppol & 0.0346885 & 0.0812606 & 0 & 0.333333 \\
\hline Ppriv & 0.119341 & 0.19732 & 0 & 0.666667 \\
\hline Pmed & 0.033691 & 0.106962 & 0 & 0.5 \\
\hline Pmod & 0.185578 & 0.333386 & 0 & 1 \\
\hline Pcont & 0.153797 & 0.255156 & 0 & 1 \\
\hline Prec & 0.626934 & 0.346687 & 0 & 1 \\
\hline Joi & 1.27731 & 1.93098 & 0 & 7 \\
\hline Pjoi & 0.367389 & 0.547863 & 0 & 3 \\
\hline
\end{tabular}

We obtained data related to the technological distance through OEPM's database again. It contains a field that assigns patents to the eight sections of the International Patent Classification (IPC). We distributed university patents through this field, which may classify patents in more than one section. When this happens, we opted to assign one patent per section. We made a second query to identify all patents applied for by Spanish residents other than universities and repeated the process to distribute them by IPC technological classes. Finally, we built the following vector of variables:

$T D_{i}$ : absolute difference of the ratio of number of university patent sections in IPC section $i$ to total university patents, minus the ratio of the number of other institutions' patent sections in IPC section $i$ to other institutions' total patents, following this formula:

$$
T D_{i}=\left|\frac{s_{i}^{u}}{\sum_{i=A}^{H} s_{i}^{u}}-\frac{s_{i}^{o}}{\sum_{i=A}^{H} s_{i}^{o}}\right|, i=A, \ldots, H
$$

\footnotetext{
${ }^{4}$ For the estimations we took non-proportion variables (herd, fte, num, joi) in logs (lherd, Ifte, lnum, ljoi).
} 
Where $s$ is the number of sections, $u$ stands for university and $o$ for other institutions.

In Table 3 we observe that the sections with the highest technological distance are those where the university is more specialised, C and G, plus one from other institutions, B. The lowest technological distance corresponds to D, E, F and H, plus A. Notice that we can roughly link IPC sections to Pavitt's (1984) sectoral taxonomy. Sections A, D and E are more likely to be applied in supplier dominated sectors, $\mathrm{B}$ and $\mathrm{F}$ in production intensive sectors and C, $\mathrm{G}$ and $\mathrm{H}$ in science-based sectors.

Table 3. Patent sections and technological distance by IPC section

\begin{tabular}{lllll}
\hline IPC code & IPC name & Universities & Other institutions & Technological distance \\
\hline A & Human Necessities & $19.95 \%$ & $23.27 \%$ & $3.31 \%$ \\
\hline B & Performing Operations; Transporting & $11.42 \%$ & $25.27 \%$ & $13.85 \%$ \\
\hline C & Chemistry; Metallurgy & $32.22 \%$ & $10.47 \%$ & $21.75 \%$ \\
\hline D & Textiles; Paper & $0.90 \%$ & $2.38 \%$ & $1.48 \%$ \\
\hline E & Fixed Constructions & $1.64 \%$ & $9.23 \%$ & $7.59 \%$ \\
\hline F & Mechanical Engineering; Lighting; Heating; & $3.28 \%$ & $9.85 \%$ & $6.57 \%$ \\
\hline G & Peapons; Blasting & $22.95 \%$ & $11.40 \%$ & $11.55 \%$ \\
\hline Physics & Electricity & $7.63 \%$ & $8.13 \%$ & $0.50 \%$ \\
\hline Total & & $100 \%$ & $100 \%$ & \\
\hline
\end{tabular}

Source: www.wipo.int/classifications/en and own elaboration.

\section{Results}

We show the final reduced models directly in Table 4. Notice for count data models that negative binomial was always preferred to Poisson and zero inflated negative binomial.

According to Column 1, there is empirical evidence that Hypothesis 1 is valid, since the variable of $R \& D$ expenditure indicates that a one percent increase in $R \& D$ funds will increase the number of university patents more than $2 \%$. In previous results by Payne and Siow (2003) and Coupé (2003) such increase was not higher than 1\%. The explanation may lie in their use of public funding rather than all funding. However, Azagra et al. (2003, 2005) also use all 
funding but find lower elasticity for R\&D funds. A second explanation may be, then, the unit of observation. Adams and Griliches (2000) find that research output of US universities follows diminishing returns to scale at the individual level but constant returns at the aggregate level. Hence, having an elasticity higher than one may differ from the relevant literature because we treat our sample data at a higher level of aggregation.

Table 4. Discrete choice estimation of Spanish university patents by route $(\mathrm{N}=238)$

\begin{tabular}{|c|c|c|c|c|}
\hline & $\begin{array}{l}1 \\
\text { Negative Binomial } \\
\text { Regression } \\
\end{array}$ & $\begin{array}{l}2 \\
\text { Negative Binomial } \\
\text { Regression } \\
\end{array}$ & $\begin{array}{l}3 \\
\text { Negative Binomial } \\
\text { Regression } \\
\end{array}$ & $\begin{array}{l}4 \\
\text { Binomial Probit } \\
\text { Model } \\
\end{array}$ \\
\hline Dependent variable & Natpat & Natgrant & Intpat & Intpat2 \\
\hline Log likelihood function & -517.24 & -504.33 & -137.62 & -82.78 \\
\hline \multirow[t]{2}{*}{ Prob[ChiSqd > value] } & 0.00 & 0.00 & 0.00 & 0.00 \\
\hline & Coeff. & Coeff. & Coeff. & Coeff. \\
\hline Constant & $-143.71(-6.64)$ & $-8.04(-10.21)$ & $-14.75(-7.33)$ & $-6.47(-4.97)$ \\
\hline Lherd & $2.17(20.68)$ & $2.2(13.82)$ & $2.98(6.99)$ & $1.36(5.01)$ \\
\hline Trend & $0.07(6.26)$ & & & \\
\hline $\mathrm{TD}_{\mathrm{B}}$ & $-1.14(-3.13)$ & $-0.98(-1.82)$ & & $-2.58(-2.38)$ \\
\hline$T_{\mathrm{F}}$ & $-1.64(-2.71)$ & $-2.11(-2.16)$ & & \\
\hline Dispersion parameter $\alpha$ & $0.09(4.31)$ & $0.55(5.97)$ & $1.5(2.71)$ & \\
\hline
\end{tabular}

The data do not confirm Hypothesis 2, i.e. the number of university researchers does not seem to influence the number of patents issued in Spain. Hence, we drop this and other variables without a significant effect off from the model and they do not appear in the table.

The data give evidence to support Hypothesis 3, i.e. for natpat, we find the time trend significant, meaning that there are exogenous factors which produce more patenting.

The data do not support Hypothesis 4, i.e. university structure does not influence the production of national university patents. ${ }^{5}$

\footnotetext{
${ }^{5}$ We tried to combine both specifications, change the benchmark and even created another variable which was the average age of universities in the region. No alternative modified the result.
} 
Again, the data do not support Hypothesis 5 -the production of national university patents is not influenced by joint research structure, whether expressed as the number of centres or as their ratio to the number of universities.

Regarding Hypothesis 6, for natpat we also find that the technological distances $T D_{B}$ and $T D_{F}$ are significant with negative sign. Let us recall that Sections B and $\mathrm{F}$ are more likely to be applied in production intensive sectors. Hence, if catching-up with regional competences is a motivation behind university patenting, it is particularly so in these technologies. ${ }^{6}$

The results of granted national patents are found in Table 4, Column 2 . The only difference with applications in is the absence of the linear trend that decreases the support to Hypothesis 3. The reason might be that the exogenous factors increase the number of patent applications that will not be granted, i.e. probably lower quality patents. Henderson et al. (1998) and Mowery and Ziedonis (2002) find somewhat similar results in the US case, regarding the declining quality of university patents.

We present the results for intpat in Table 4, Column 3. Hypothesis 7 is rejected by the data, i.e. the number of past national university patents does not imply anything for the number of international university patents. This may mean that universities apply so much through the national route that they do not aim to extend most applications through the international route.

For Spanish universities the only coincident significant determinant of national and international patents is $R \& D$ expenditure. However, there is also some evidence to support Hypothesis 8 since some determinants are not significant in either case: number of researchers, university structure, number of joint research centres and technological distances

\footnotetext{
${ }^{6}$ Since technologies in sections B and F may have in common the likelihood of being applied in production intensive sectors, we wondered whether we find this econometric effect because patents classified in section B are also classified in F. Our analysis shows that this is rarely the case.
} 
other than B and F. Finally, there is evidence to reject Hypothesis 8 in the sense that the trend and technological distances B and F are not significant in the case of international patents.

Our estimate for the coefficient of $R \& D$ expenditure indicates that a one percent increase of the variable will produce a nearly $3 \%$ increase in international patents. Via a Wald test, at $5 \%$ significance level we cannot reject that the coefficients of R\&D for national and international patents are equal, while at $10 \%$ we can. In short, there is some evidence that the coefficient of R\&D expenditure for international patents is higher than for national ones, but it is weak.

Finally, Table 4, Column 4, shows results from intpat2. Once more, there is no evidence to support Hypothesis 7 and there is ambiguous evidence to support Hypothesis 8. The probit and NBRM models have very similar results, and in both of them the coefficient of R\&D expenditure is significant. Note however, that in the probit model for intpat2 the variable $T D_{B}$, the one with the lowest technological distance, appeared significant.

\section{Conclusions}

Three main interests guided this research: Do we confirm the common empirical results on university patents at regional level? Can regions as a unit of observation offer other stimulating findings? Do the answers vary whether we study national or international routes of patenting? The answer is affirmative in every case.

According to our results, university national patents are an indicator of R\&D efforts also when we focus on the region, but they are not an indicator of how regions organize their university or joint research structure. Therefore, if there is a re-composition of academic R\&D favouring patentable results and if regions cannot control their academic structure to compensate for it, e.g. by favouring the predominance of institutions less prone to select this kind of $R \& D$, the fear of unintended consequences could be justified. 
On the other hand, university international patents are also an indicator of R\&D efforts, with incipient evidence of a stronger reaction than national patents. If confirmed, this would be congruent with the fact that international application procedures are more costly and require greater confidence in the potential of the results of academic $R \& D$. Our results corroborate that this confidence relies on higher investment in R\&D. However, as in the case of national patents, international patents do not depend on the university or joint research structure of the region. And naturally, catching-up with other institutions in the region is an even less important motivation for applying for through international procedures.

Let us recall that neither set of patents is an indicator of technological catching-up with the region in technologies other than for production intensive sectors. Hence, if university patents are a measure of technology transfer potential, this does not necessarily mean regional technology transfer, at least in supplier dominated and science-based sectors.

Incidentally, we have confirmed that the use of both national and international patents is advisable when studying universities' patenting activities, since they depend on different determinants.

\section{Acknowledgements}

We would have never done this research without support from Ignacio Fernández-de-Lucio and Antonio Gutiérrez-Gracia. Elena Castro-Martínez provided substantial help to find data. Fernando Jiménez-Sáez offered useful comments. We are obliged to them.

\section{References}

Adams, J. D. and Z. Griliches (2000): "Research Productivity in a System of Universities”, in Encaoua D., B. H Hall., F. Laisney and J. Mairesse (eds.): The Economics and Econometrics of Innovation, Kluwer Academic Publishers, Dordrecht, The Netherlands. 
Agrawal, A., R. Henderson (2002): "Putting Patents in Context: Exploring Knowledge Transfer from MIT”, Management Science 48 (1): 44-60.

Azagra-Caro, J., I. Fernández-de-Lucio and A. Gutiérrez-Gracia (2003): “University patents: output and input indicators... of what?”, Research Evaluation 12 (1): 5-16.

Azagra-Caro, J., N. Carayol and P. Llerena (2005): "Patent Production at a European Research University: Exploratory Evidence at the Laboratory Level”, Journal of Technology Transfer, forthcoming.

Carlsson, B. and A. C. Fridh (2002): “Technology Transfer in the United States Universities”, Journal of Evolutionary Economics 12, 199-232.

Cesaroni, F. and Piccaluga, A. (2002): "Patenting activities of European Universities. Relevant? Growing? Useful?”, SPRU NPRnet Conference “Rethinking Science Policy”. Brighton (UK), 21-23 March.

Clark, B. R. (1998): Creating Entrepreneurial Universities, Guilford: IUA Press, Pergamon.

Coupé, T. (2003): “Science is Golden: Academic R\&D and University Patents”, Journal of Technology Transfer 28, 31-46.

Dasgupta, P. and P. David (1994): “Towards a new economics of science”, Research Policy 23 (5): 487-521.

Etzkowitz, H. (1998): “The norms of entrepreneurial science: cognitive effects of the new university-industry linkages”, Research Policy 27: 823-833.

Foltz, J., B. Barham and K. Kim (2000): “Universities and Agricultural Biotechnology Patent Production”, Agribusiness 16 (1), 82-95.

Foltz, J., K. Kim and B. Barham (2001): “A Dynamic Count Data Analysis of University AgBiotech Patents”, Food Marketing Policy Center Research Report 56.

Geuna, A. (1999): The Economics of Knowledge Production, Cheltenham and Northampton: Edward Elgar. 
Henderson, R., Jaffe, A. B. and Trajtenberg, M. (1998): "Universities as a source of commercial technology: A detailed analysis of University Patenting, 1965-1988”, Review of Economics and Statistics 80 (1): 119-27.

Meyer, M. (2004): "Measuring Science-Technology Interaction in the Knowledge-Driven Economy”, Book of Abstracts of the $8^{\text {th }}$ International Conference on Science and Technology Indicators, Leiden 23-25 September 2004.

Meyer-Krahmer, F. and U. Schmoch (1998): "Science-based technologies: university-industry interactions in four fields”, Research Policy 27: 835-51.

Mowery, D. C. and B. N. Sampat (2001): "University Patents and Patent Policy Debates in the USA, 1925-1980”, Industrial and Corporate Change 10 (3): 781-814.

Mowery, D. C. and A. A. Ziedonis (2002): “Academic patent quality before and after the Bayh-Dole act in the United States”, Research Policy 31: 399-418.

Pavitt, K. (1984): "Sectoral patterns of technical change: Towards a taxonomy and a theory”, Research Policy 13: 343-373.

Payne, A. A. and A. Siow (2003): "Does Federal Research Funding Increase University Research Output?”, Advances in Economic Analysis \& Policy 3 (1), Article 1.

Rodríguez-San Pedro, L. E. (2004): "Las Universidades hispanas en su contexto histórico”, http://www.universia.es/contenidos/universidades/historia/Universidades_historia.htm.

Scott, A., G. Steyn, A. Geuna, S. Brusoni and E. Steinmueller (2002): The Economic Returns to Basic Research and the Benefits of University-Industry Relationships: A literature review and update of findings, SPRU: Report for the Office of Science and Technology. 